\title{
Pregnancy outcome in rheumatic mitral stenosis patients with and without surgical correction: a prospective cohort study
}

\author{
Mustafa Bahloul, Armia Michael, Mansour Y. Kandeel, Ahmed M. Abbas*
}

Department of Obstetrics and Gynecology, Faculty of Medicine, Assiut, Egypt

Received: 29 March 2017

Accepted: 27 April 2017

\section{*Correspondence:}

Dr. Ahmed M. Abbas,

E-mail: bmr90@hotmail.com

Copyright: (c) the author(s), publisher and licensee Medip Academy. This is an open-access article distributed under the terms of the Creative Commons Attribution Non-Commercial License, which permits unrestricted non-commercial use, distribution, and reproduction in any medium, provided the original work is properly cited.

\section{ABSTRACT}

Background: The aim of the current study is to assess the maternal and fetal outcomes of pregnant females with and without surgically corrected mitral stenosis (MS).

Methods: A cross sectional study was carried out at Assiut Women's Health Hospital, Egypt between February 2016 and December 2016. All pregnant women diagnosed with rheumatic heart disease attending the antenatal care clinic were enrolled in the study. They were divided into two groups according to previous surgical correction of MS or not. All women were followed up during pregnancy till the end of puerperium. The primary outcome of the study was the difference in the rate of maternal cardiac complications during pregnancy between both groups.

Results: The study included 48 patients (39\%) with surgically corrected MS and 75 patients (61\%) with uncorrected MS. All cardiac complications were significantly higher in the uncorrected MS group ( $\mathrm{p}<0.05$ ). No difference between both groups in the mode of delivery $(\mathrm{p}=0.52)$. Postpartum hemorrhage is more common with the corrected MS group than the uncorrected group ( $25 \%$ vs. $9.3 \%$ respectively, $\mathrm{p}=0.003$ ), while the need for postpartum admission to ICU was significantly higher in the uncorrected group $(\mathrm{p}=0.006)$. The mean birth weight was higher in the corrected MS group ( $\mathrm{p}=0.000)$. The percentage of stillbirths and the rate of admission to PCU was higher in the uncorrected MS group $(\mathrm{p}=0.003)$.

Conclusions: Surgical correction of MS significantly improves the maternal and fetal outcomes of rheumatic heart pregnant females with MS.

Keywords: Maternal morbidity, Mitral replacement, Perinatal outcome, Rheumatic heart disease

\section{INTRODUCTION}

Pregnancy is associated with several hemodynamic changes that can significantly affect a preexisting cardiac disease; including sodium and water retention which increase the cardiac output, and decrease the systemic vascular resistance and systemic blood pressure. ${ }^{1}$ These changes start in the first five to eight weeks of pregnancy, maximize during the late second trimester, and then remain relatively steady until delivery.

Heart disease is one of the important medical complications in pregnant females as it is a common indirect obstetric cause of maternal morbidity and mortality. About 2-4\% of pregnant females are suffering from cardiac disease. ${ }^{2}$ Rheumatic heard disease (RHD) is a consequence of acute rheumatic fever. It stills a major cause of cardiac morbidity and mortality in developing countries particularly among young adult women. ${ }^{3,4}$

The most common valvular lesion in females with RHD is mitral stenosis (MS). It remains the most common acquired valvular lesion in pregnant females and the most common cause of maternal death from cardiac causes. ${ }^{5,6}$ Even though mortality is not high in rheumatic pregnant females, the rate of fetal morbidity is positively 
correlated with the severity of MS from as it increases from $14 \%$ in pregnant females with mild MS to $28 \%$ in those with moderate MS and $33 \%$ in females with severe $\mathrm{MS}^{7,8}$

Surgical correction of MS includes mitral commissurotomy and percutaneous balloon valvuloplasty in mild and moderate cases. ${ }^{9}$ Lastly, valve replacement is reserved for the severe cases. ${ }^{10}$ Pregnancy after mitral valve replacement is very risky for both mother and fetus as a result of the aggravation of maternal heart function and adverse effects of anticoagulation therapy. Potential risks include maternal heart failure, arrhythmia, infective endocarditis, and high risk of maternal mortality with advancing gestational age. ${ }^{11}$

The aim of the current study was to assess the maternal and fetal outcomes of pregnant females with and without surgically corrected mitral stenosis.

\section{METHODS}

\section{Study type, setting and duration}

The current study was a prospective cohort study conducted at Assiut Women's Health Hospital, Egypt between February 2016 and December 2016. The Assiut Medical School Ethical Review Board approved the study. The non-interventional nature of the study and respect of patients' confidentiality were clear to the patient and their written consent to participate had been obtained.

\section{Study population}

All pregnant women diagnosed with rheumatic heart disease attending the antenatal care clinic of the aforementioned hospital during the study period were invited to participate in the study. The inclusion criteria were; age 15-40 years, pregnant at any trimester, proven diagnosis of MS by recent echocardiography or patient had a full surgical report confirming the intervention done for correction of MS. We excluded women with other valve lesions, those who had chronic medical illnesses as diabetes and hypertension, women with congenital or ischemic heart diseases and those who declined participation in the study.

\section{Intervention}

One of the study investigators collected the basic data including; age, parity, previous miscarriages and body mass index (BMI). Then, a detailed history was taken regarding the antenatal visits, anticoagulation regimen, use of long acting penicillin, obstetric history, previous heart failure and history of intensive care unit (ICU) admission before.

Thorough clinical examination was done to find out the type of cardiac lesion, any signs of failure and stage of pregnancy. Cases were graded as per NYHA classification of grade of heart disease. Cases were referred to a cardiologist for confirmation of cardiac disease; know the functional status of the heart through evaluation by echocardiography to evaluate the presence of pulmonary hypertension. All included patients were classified into two groups; surgically corrected cases and surgically uncorrected cases.

\section{Follow-up}

All women were followed up during pregnancy till the end of puerperium according to the hospital protocol. Any cardiac or obstetric complications occurred during pregnancy was recorded. Data at delivery was obtained including; gestational age at delivery, mode of delivery and use of anesthesia. Additionally; fetal weight, gender, Apgar score at delivery, presence of congenital malformations and need for pediatric care unit admission (PCU) were recorded.

The need for postpartum admission to ICU, duration of hospital stay and cases of maternal mortality were also recorded.

\section{Study outcomes}

The primary outcome of the study was the difference in the rate of maternal cardiac complications during pregnancy as heart failure, arrhythmia between both groups. The secondary outcomes were the difference in the rate of obstetric complications, mode of delivery, fetal birth weight, rate of neonatal complications, perinatal and maternal mortality.

\section{Statistical analysis}

The collected data was coded; tabulated and analyzed using the statistical package for social science programs (SPSS) Chicago, IL, USA, version 22. Quantitative variables were expressed as mean and standard deviation. Qualitative variables were expressed as frequency and percentage. Comparison between groups was done using Student's T-test for quantitative variables and chi-square test for qualitative variables. Level of significance "P" value was evaluated, where $\mathrm{P}$ value $<0.05$ was considered statistically significant.

\section{RESULTS}

One hundred and forty-eight women were approached to participate in this study. Twenty-five women were excluded due to presence of different exclusion criteria or their refusal to participate in the study. The remaining 123 women were stratified into two groups; 48 patients (39\%) with surgically corrected MS and 75 patients $(61 \%)$ with uncorrected MS. Of the 48 surgically corrected cases; 34 women (70.8\%) had performed mechanical mitral valve replacement and 14 women (29.2\%) with balloon valvuloplasty. 
Table 1: The basic and clinical data of the study participants.

\begin{tabular}{|c|c|c|c|c|c|}
\hline \multirow{3}{*}{ Variables } & \multicolumn{4}{|c|}{ Rheumatic MS (n=123) } & \multirow{3}{*}{ p-value } \\
\hline & \multicolumn{2}{|c|}{ Corrected } & \multicolumn{2}{|c|}{ Uncorrected } & \\
\hline & $n=48$ & $\%$ & $n=75$ & $\%$ & \\
\hline Age (years) $\#$ & $29.4 \pm 5.5$ & & $29.2 \pm 5.2$ & & 0.25 \\
\hline Parity \# & $2.0 \pm 1.6$ & & $2.3 \pm 1.7$ & & 0.31 \\
\hline $\mathrm{BMI}^{\#}$ & $22.9 \pm 1.9$ & & $22.8 \pm 2.6$ & & 0.76 \\
\hline Previous miscarriages ${ }^{\#}$ & $0.70 \pm 0.9$ & & $0.52 \pm 0.9$ & & 0.32 \\
\hline Regular ANC & 42 & 87.5 & 66 & 88 & 0.57 \\
\hline \multicolumn{6}{|l|}{ Medications } \\
\hline Long acting penicillin & 32 & 66.7 & 53 & 70.7 & 0.69 \\
\hline Heparin & 28 & 58.3 & 4 & 5.3 & $0.000 *$ \\
\hline Oral anticoagulants & 9 & 18 & 3 & 4 & $0.04 *$ \\
\hline History of ICU admission & 2 & 4.2 & 5 & 6.7 & 0.70 \\
\hline Previous heart failure & 2 & 4.2 & 7 & 9.3 & 0.48 \\
\hline \multicolumn{6}{|l|}{ NYHA classification } \\
\hline Grade 1 & 33 & 68.8 & 21 & 28 & \multirow{4}{*}{$0.000 *$} \\
\hline Grade 2 & 12 & 25 & 32 & 42.7 & \\
\hline Grade 3 & 2 & 4.2 & 19 & 25.3 & \\
\hline Grade 4 & 1 & 2.1 & 3 & 4 & \\
\hline
\end{tabular}

MS; mitral stenosis, BMI; body mass index, ANC; antenatal care, ICU; intensive care unit, $(*)$ statistically significant difference, $(\#)$ Data are presented as mean \pm standard deviation

Table 1 show that both groups were homogenous in their basic and clinical data on admission. Patients in the corrected MS group were more receiving anticoagulants in the form of oral tablets or subcutaneous heparin than the uncorrected group (18\% vs. $4 \%$ and $58.3 \%$ vs. $5.3 \%$, respectively) with a statistical significant difference. More than two-thirds of patients $(68.8 \%)$ in the corrected MS group were NYHA class I, while most of uncorrected MS group $(42.7 \%)$ were NYHA class II $(\mathrm{p}=0.000)$.

Table 2: The maternal outcomes during pregnancy, labor and puerperium.

\begin{tabular}{|c|c|c|c|c|c|}
\hline \multirow{3}{*}{ Outcomes } & \multicolumn{4}{|c|}{ Rheumatic MS (n=123) } & \multirow{3}{*}{ p-value } \\
\hline & \multicolumn{2}{|c|}{ Corrected } & \multicolumn{2}{|c|}{ Uncorrected } & \\
\hline & $n=48$ & $\%$ & $n=75$ & $\%$ & \\
\hline \multicolumn{6}{|l|}{ Cardiac complications } \\
\hline Heart failure & 1 & 2.1 & 15 & 20 & $0.003 *$ \\
\hline Mild pulmonary hypertension & 9 & 18.8 & 23 & 30.7 & $0.008 *$ \\
\hline Severe pulmonary hypertension & 0 & 0 & 8 & 10.7 & $0.000 *$ \\
\hline Arrhythmia & 0 & 0 & 2 & 2.7 & $0.01 *$ \\
\hline Infective endocarditis & 0 & 0 & 0 & 0 & --- \\
\hline \multicolumn{6}{|l|}{ Mode of delivery } \\
\hline Spontaneous vaginally & 20 & 41.7 & 31 & 41.3 & \multirow{4}{*}{0.52} \\
\hline Induced vaginally & 2 & 4.2 & 5 & 6.7 & \\
\hline Elective CS & 19 & 39.6 & 25 & 33.3 & \\
\hline Urgent CS & 7 & 14.5 & 14 & 18.7 & \\
\hline Anesthesia during CS & $\mathrm{n}=26$ & & $\mathrm{n}=39$ & & \multirow{3}{*}{0.06} \\
\hline Spinal & 22 & 84.6 & 29 & 74.4 & \\
\hline General & 4 & 15.4 & 10 & 25.6 & \\
\hline Postpartum hemorrhage & 12 & 25 & 7 & 9.3 & $0.003 *$ \\
\hline Postpartum Admission to ICU & 6 & 12.5 & 36 & 48 & $0.006 *$ \\
\hline $\begin{array}{l}\text { Duration of postpartum hospital } \\
\text { stay (days) } \#\end{array}$ & \multicolumn{2}{|l|}{$2.9 \pm 2.1$} & \multicolumn{2}{|l|}{$4.9 \pm 4.5$} & $0.001 *$ \\
\hline Maternal deaths & 1 & 2.1 & 2 & 2.7 & 0.59 \\
\hline
\end{tabular}

MS; mitral stenosis, CS; cesarean section, ICU; intensive care unit, (*) statistically significant difference, (\#) Data are presented as mean \pm standard deviation 
Table 3: The neonatal outcomes of the study participants.

\begin{tabular}{|c|c|c|c|c|c|}
\hline \multirow{3}{*}{ Outcomes } & \multicolumn{4}{|c|}{ Rheumatic MS (n=123) } & \multirow{3}{*}{ p-value } \\
\hline & \multicolumn{2}{|c|}{ Corrected } & \multicolumn{2}{|c|}{ Uncorrected } & \\
\hline & $n=48$ & $\%$ & $n=75$ & $\%$ & \\
\hline Birth weight (gram) ${ }^{\#}$ & \multicolumn{2}{|c|}{$3304.8 \pm 365.6$} & \multicolumn{2}{|c|}{$2553.6 \pm 544.7$} & $0.000^{*}$ \\
\hline Apgar score $\#$ & \multicolumn{2}{|c|}{$9.45 \pm 0.74$} & \multicolumn{2}{|c|}{$7.65 \pm 2.82$} & $0.000 *$ \\
\hline \multicolumn{6}{|l|}{ Neonatal gender } \\
\hline Male & 26 & 54.2 & 41 & 54.7 & \multirow{2}{*}{0.85} \\
\hline Female & 22 & 45.8 & 34 & 45.3 & \\
\hline Stillbirths & 0 & 0 & 6 & 8 & $0.003^{*}$ \\
\hline Congenital malformations & 0 & 0 & 0 & 0 & ----- \\
\hline Admission to PCU & 1 & 2.1 & 12 & 16 & $0.003 *$ \\
\hline
\end{tabular}

MS; mitral stenosis, PCU; pediatric care unit, $\left(^{*}\right)$ statistically significant difference, (\#) Data are presented as mean \pm standard deviation

Table 2 summarizes the maternal outcomes of rheumatic MS patients during pregnancy, labor and puerperium. Apart from infective endocarditis, all cardiac complications were significantly higher in the uncorrected MS group ( $\mathrm{p}<0.05$ ). No difference between both groups in the mode of delivery $(\mathrm{p}=0.52)$. Postpartum hemorrhage is more common with the corrected MS group than the uncorrected group (25\% vs. $9.3 \%$ respectively, $\mathrm{p}=0.003$ ), while the need for postpartum admission to ICU was significantly higher in the uncorrected group $(\mathrm{p}=0.006)$.

Table 3 demonstrates a statistical significant difference between both groups as regard the neonatal outcome. The mean birth weight was higher in the corrected MS group $(p=0.000)$. The percentage of stillbirths and the rate of admission to PCU was higher in the uncorrected MS group $(\mathrm{p}=0.003)$.

\section{DISCUSSION}

The current study demonstrated that the surgically corrected MS patients have better maternal and neonatal outcomes during the course of pregnancy and labor than the uncorrected MS patients. Postpartum hemorrhage is the only concern in the corrected MS patients which is attributed to the unadjusted use of anticoagulants during pregnancy.

Typical pregnancy hemodynamic changes include a 40$50 \%$ increase in blood volume and cardiac output by midterm, accompanied by vasodilation and an increase in heart rate of $10-15$ beats/min. ${ }^{12}$ Labor and delivery pose an additional cardiovascular burden due to contractions, pushing and the auto transfusion that occurs after delivery. ${ }^{13}$ Although these changes are well tolerated by most women, in those with significant RHD, there may be adverse cardiovascular effects that can result in maternal or fetal morbidity or even death. ${ }^{14}$

The most common heart valves affected by RHD and non-RHD causes are the mitral and aortic valves, less commonly the tricuspid and rarely the pulmonary valve. Rheumatic valve disease most commonly leads to regurgitation and less commonly to valve stenosis or mixed regurgitation and stenosis. ${ }^{15-17}$ Although the majority of rheumatic valve disease cases are only mildly affected, a minority progress to more severe disease requiring valve surgery. ${ }^{18}$

MS remains the most common acquired valvular lesion in pregnant women and the most common cause of maternal death from cardiac causes worldwide. ${ }^{6}$ The rate of fetal morbidity, including fetal growth restriction and preterm birth, rises with the severity of MS from $14 \%$ in pregnant patients with mild MS, to 28 and $33 \%$ in pregnant patients with moderate and severe MS, respectively. ${ }^{19}$

In present study, there were 34 patients $(27.6 \%)$ of 123 rheumatic pregnant females included were undergone mitral valve replacement, and 14 patients (11.4\%) were undergone valvoplasty (balloon dilatation). Regarding the mode of delivery and antenatal care, there was no significant difference between modes of delivery in both groups.

Madazli et al reported in a retrospective analysis including 144 pregnancies in women with cardiac disease that there were no cases of maternal mortality and cardiac women with no intervention have poorer maternal outcome with more complications as heart failure, arrhythmias, and admission to cardiac ICU when compared to those with intervention. ${ }^{20} \mathrm{We}$ are keeping in the same track with their results. However; in our study, postpartum hemorrhage is more common in surgically corrected patients $(33.3 \%)$ than those with no surgery $(9.3 \%)$. This can be attributed to their use of warfarin and heparin more than those with no intervention $(58.3 \%$ vs. $5.3 \%)$ and (18\% vs. $4 \%)$ respectively.

In present study, patients with no intervention had significantly higher rate of cardiac complications during pregnancy as heart failure and arrhythmia after termination of pregnancy than those with intervention. 
There are 3 cases of maternal mortality, one case in surgically corrected patients and 2 cases in those with no intervention.

The physiological changes of pregnancy can precipitate symptoms of cardiac disease in women who were previously asymptomatic. In our study, surgically corrected patients are less symptomatic than those with uncorrected MS. Additionally, patients with no intervention have poorer neonatal outcome as birth weight and Apgar score than those in patients with intervention. Pediatric care unit admission and stillbirths were significantly $(\mathrm{p}=0.000)$ more in patients with no intervention.

In conclusion, surgical correction of MS either by valve replacement of valvoplasty improves the maternal and fetal outcomes in rheumatic heart pregnant females. Optimization of the received anticoagulants doses can decline the rate of postpartum hemorrhage in those patients.

\section{Funding: No funding sources}

Conflict of interest: None declared

Ethical approval: The study was approved by the Institutional Ethics Committee

\section{REFERENCES}

1. Chapman AB, Abraham WT, Zamudio S, Coffin C, Merouani A, Young D et al. Temporal relationships between hormonal and hemodynamic changes in early human pregnancy. Kidney Int. 1998;54:2056.

2. Arnoni RT, Arnoni AS, Bonini RC, de Almeida AF, Neto CA, Dinkhuysen JJ et al. Risk factors associated with cardiac surgery during pregnancy. Ann Thorac Surg. 2203;76(5):1605-8.

3. Carapetis JR, Steer AC, Mulholland EK. The current evidence for the burden of group A streptococcal diseases (WHO/FCH/CAH/05.07). World Health Organization, Geneva; 2004.

4. Rheumatic fever and rheumatic heart disease: report of a WHO expert consultation-Geneva, 29 October-1 November 2001. WHO Technical Report Series; 2001:923.

5. Elkayam U, Bitar F. Valvular heart disease and pregnancy part I: native valves. J Am Coll Cardiol. 2005;46:223-30.

6. Stout KK, Otto CM. Pregnancy in women with valvular heart disease. Heart. 2007;93:552-8.

7. Silversides CK, Colman JM, Sermer M, Siu SC. Cardiac risk in pregnant women with rheumatic mitral stenosis. Am J Cardiol. 2003;91:1382-5.

8. Baumgartner H, Hung J, Bermejo J, Chambers JB, Evangelista A, Griffin BP et al. American Society of
E, European Association of E. Echocardiographic assessment of valve stenosis: EAE/ASE recommendations for clinical practice. J Am Soc Echocardiogr. 2009;22:1-23.

9. De Souza JA, Martinez EE Jr, Ambrose JA, Alves CM, Born D, Buffolo E, et al. Percutaneous balloon mitral valvuloplasty in comparison with open mitral valve commissurotomy for mitral stenosis during pregnancy. J Am Coll Cardiol. 2001;37:900-3.

10. Sutton SW, Duncan MA, Chase VA, Marce RJ, Meyers TP, Wood RE. Cardiopulmonary bypass and mitral valve replacement during pregnancy. Perfusion. 2005;20:359-68.

11. Chan WS, Anand S, Ginsberg JS. Anticoagulation of pregnant women with mechanical heart valves: a systematic review of the literature. Arch Intern Med. 2000;160:191-6.

12. Curry R, Swan L, Steer PJ. Cardiac disease in pregnancy. Curr Opin Obstet Gynecol. 2009;21:50813.

13. Reimold SC, Rutherford JD. Clinical practice. Valvular heart disease in pregnancy. N Engl J Med. 2003;349:52-9.

14. Chandrashekhar Y, Westaby S, Narula J. Mitral stenosis. Lancet. 2009;374:1271-83.

15. Remenyi B, Wilson N, Steer A, Ferreira B, Kado J, Kumar K et al. World Heart Federation criteria for echocardiographic diagnosis of rheumatic heart disease-an evidence-based guideline. Nat Rev Cardiol. 2012;9:297-309.

16. Enriquez-Sarano M, Akins CW, Vahanian A. Mitral regurgitation. Lancet. 2009;373:1382-94.

17. Bhandari S, Subramanyam K, Trehan N. Valvular heart disease: diagnosis and management. J Assoc Physicians India. 2007;55:575-84.

18. Baskerville CA, Hanrahan BB, Burke AJ, Holwell AJ, Remond MG, Maguire GP. Infective endocarditis and rheumatic heart disease in the north of Australia. Heart Lung Circ. 2012;21:36-41.

19. Lesniak-Sobelga A, Tracz W, KostKiewicz M, Podolec P, Pasowicz M. Clinical and echocardiographic assessment of pregnant women with valvular heart diseases-maternal and fetal outcome. Int J Cardiol. 2204;94:15-23.

20. Madazli R, Sal V, Cift T, Guralp O, Goymen A. Pregnancy outcomes in women with heart disease. Arch Gynecol Obstet. 2010;281(1):29-34.

Cite this article as: Bahloul M, Michael AM, Kandeel MY, Abbas AM. Pregnancy outcome in rheumatic mitral stenosis patients with and without surgical correction: a prospective cohort study. Int $\mathbf{J}$ Reprod Contracept Obstet Gynecol 2017;6:2342-6. 